\title{
EUGENETIKA EN DIE MEDIES-GENETIESE BEHANDELING VAN DIE MENS (IV)
}

\section{VOORTPLANTING IN PERSPEKTIEF.}

Die regverdiging van baie van die medies-genetiese navorsing $\mathrm{m} \mathrm{b} t$ voortplanting by die mens (vgl Deel II), is gegrond op die argument dat die bekamping van 'n algemene medies-sosiale euwel soos onvrugbaarheid dit noodsaak. Dié toegepaste medies-genetiese navorsing sal naamlik uiteindelik - so word aangevoer - die vooruitsigte ter oorkoming daarvan verbeter, of as alternatief, die manipulasie as sodanig is reeds die oplossing waardeur die onvrugbaarheid te bowe gekom word (vgl fetusoorplantings). Die omstrede mediesgenetiese optrede word dus deur die voorstaanders daarvan geregverdig deurdat hulle daarop wys dat individuele egpare 'n basiese reg op eie kinders sou hê. Egpare wat vanweë onvrugbaarheid nie in daardie vermeende reg deel nie, sou dus teenoor die gemeenskap aanspraak op oorkoming van hulle probleme kan maak.

Voortvloeiend uit bogenoemde, sou 'n egpaar ook selfs op 'n vermeende reg op gesonde kinders aanspraak kan maak. Die gemeenskap sou daardeur gebind wees om die nodige stappe te dien effekte te onderneem, d w s om alles te doen (alle tipes eksperimentele navorsing en behandeling) om aangebore genetiese siektes en abnormaliteite uit te skakel. Die twee grondliggende veronderstellings wat in bostaande aansprake bevat is, sal vervolgens vollediger ondersoek moet word.

\section{(a) Die reg op kinders}

Reeds sedert baie jare aanvaar inwoners van Wes-Europa 'n finansiële vergoeding wat deur die onderskeie state aan egpare ooreenkomstig hulle kindertal uitbetaal word. Globaal gesien het hierdie maatreël waarskynlik die uitwerking waarvoor dit bedoel is; die kwynende bevolkingsaanwas is sekerlik hoër as andersins. In ontwikkelende lande daarenteen word dit in die belang van die gemeenskap geag om die voortplantingspoed te beperk en pas sommige betrokke regerings dienooreenkomstige maatreëls toe. Alle maatreëls van hierdie aard stel die belange van die gemeenskap (via die staat) dus duidelik eerste. Die huidige situasie is dus gekenmerk deur'n onopvallende, indirekte beinvloeding van die vermeende private reg op ' $n$ เ willekeurige aantal kinders. In die geval van ontwikkelende lande is dit selfs al buitelandse regerings en instansies wat op die voortplanting van die betrokke bevolkings invloed probeer uitoefen. Hulpverlenende buitelandse regerings en in ternasionale instansies neem inderdaad die "demografiese kredietwaardigheid" (effektiewe ge- 
boortebeperking as voorwaarde vir ekonomiese hulpverlening) van ontwikkelende lande in aanmerking alvorens hulpverlening oorweeg word.

Aan die ander kant is dit ook die individuele inwoners van state wat op alle vlakke (kraaminrigtings, hospitale, kleuterskole, skole universiteite, spesiale inrigtings en andere) aanspraak op openbare ondersteuning en dienste vir hulle kinders maak. Gesien uit 'n geskiedkundige oogpunt, is 'n duidelike neiging tot "sosialisering" waarneembaar; 'n ontwikkeling wat vandag byvoorbeeld in WesEuropa baie duidelik tot uiting kom. Ingevolge hierdie proses is dit die staat wat al hoe meer tot verantwoording geroep en vir die belange van die gemeenskapslede ingespan word. Ooreenkomstig die oorname van individuele verantwoordelikhede en verpligtinge is die staat besig om individuele regte in te palm en te kortwiek. Een van die individuele regte wat hier in die gedrang kom is juis die vermeende reg op vryelike voortplanting. Samevattend blyk dit dus dat sowel die belang wat die staat in die voortplantingspatroon van sy onderdane het, asook die neiging van individuele gemeenskapslede om hulle verantwoordelikhede en verpligtinge in die hande van die staat te plaas, daartoe gelei het dat een van die vermeende basiese private regte, naamlik dié op willekeurige voortplanting reeds ingekort is.

Teen hierdie agtergrond is dit verstaanbaar dat baie deskundiges nadruklik daarop wys dat die verwekking van kinders nie uitsluitlik 'n private aangeleentheid mag wees nie. Inteendeel, daar word geëis dat elke land sy bevolkingsaan was ' $n$ aangeleentheid van amptelike beleid, wat onder staatsbeheer behoort te staan, moet maak, terwyl gesinsbeplanning by die verpligte openbare mediese dienste van elke staat ingesluit behoort te word. Vir die toekoms word vervolgens voorsien dat die individuele voortplantingspatroon volkome deur die staat gekontroleer word. Ingevolge 'n amptelike "voortplantingsbeleid" en met inagneming van openbare belange is dit uiteindelik denkbaar dat egpare slegs die reg op 'n sekere "kwota" kinders toegeken word. Indien dit wenslik geag word kan hierdie "kwota" ooreenkomstig eugenetiese oorwegings selfs oneweredig versprei wees. Sommige egpare sal dan moontlik hoegenaamd nie durf voortplant nie, terwyl ander moontlik 'n groter getal kinders as die gemiddelde mag nalaat. Die vraag na die praktiese implementering van 'n sodanige stelsel het ook reeds aandag gekry; daar is 'n aantal effektiewe moontlikhede onder bespreking. 
Op hierdie punt moet pertinent gevra word of sodanige drastiese manipulasie moreel-sedelik toelaatbaar is. Gesaghebbendes - soos byvoorbeeld die Nobelpryswenner Crick - ontken die vermeende algemene reg op kinders wat elke mens ipso facto sou hê:

This (die reg op kinders) is taken for granted because it is part of Christian ethics, but in terms of humanist ethics I do not see why people should have the right to have children.

Dus, in die lig van die algemene historiese ontwikkeling en die probleme van oorbevolking wat tans die voortgesette oorlewing op aarde in gevaar stel, tree - volgens Crick en andere - die imperatief van 'n "humanistiese etiek" op die voorgrond ingevolge waarvan die enkeling geen basiese reg op willekeurige voortplanting sou hê nie. Crick meen dat hierdie "humanistiese etiek" in botsing met die Christelike etiek sou wees, maar dit wil voorkom asof hierdie stelling nie 'n uitgemaakte saak is nie.

Die Calvinis Bloemhof het hierdie probleem vanuit 'n Christelike standpunt benader. Hy kom tot die gevolgtrekking dat met die geboorte van Christus die opdrag van God uit die Ou Testament, "Wees vrugbaar en vermenigvuldig..." (Genisis 1:28), om kinders te verwek, verval het.

Welnu, vanuit de Persoon en het Werk van Jezus Christus gezien is het helemaal niet meer 'nodig', dat er kinderen geboren worden. Want in Hem is hét kind gekomen. Christelijk gezien is het helemaal niet meer nodig, dat de geschiedenis van de mensen voortgang vindt en de lijn der geslachten doorgetrokken wordt. Want de geschiedenis heeft principieel haar doel en hoogtepunt gevonden in Hem. Christelijk gezien heeft niemand het recht noch de plicht kinderen te verwekken of ter wereld te bringen. Wij behoeven niet te zorgen, dat de mensheid in stand gehouden wordt en de geschiedenis voortgang heeft. Wammeer de mensheid in stand gehouden wordt en de geschiedenis nog voortgang vindt, heeft dat zijn oorsprong in het feit, dat God in Zijn

Geduld ons de mogelijkheid tot leven nog schenkt en de geschiedenis nog laat voortgaan.

Indien hierdie teksuitlegging aanvaar word, blyk dit dat die mens uit die oogpunt van die Christelike etiek en in ooreenstemming met die "humanistiese etiek" nie aanspraak op 'n basiese reg op kinders kan maak nie. Die voortplantingspatroon binne 'n gemeenskap is dus blykbaar nie ' $n$ prinsipiële etiese maar ' $n$ pragmatiese aangeleen theid 
wat ooreenkomstig die arbitrêre moreel-sedelike waardesisteem van 'n gemeenskap van tyd tot tyd gereël word. Verder word bepleit om meer bepaald ook praktiese sosiale en demografiese probleme van elke geskiedkundige tydperk en gemeenskap in aanmerking te neem. As antwoord op Edwards en Sharpe se verweer - dat oorbevolking eweseer die verpligting op alle mense plaas om minder kinders te hê en om nie verdere hulp aan kinderlose egpare met hierdie argument te ontsê nie - word byvoorbeeld aangevoer ". . . but in an overcrowded world infertility is an individual problem, not a great social issue" (Editorial, 1971). Hiermee is beklemtoon dat onder sekere omstandighede sosiaal-demografiese belange (naas die moreel-sedelike waardesisteem van 'n gemeekskap) bo ' $n$ vermeende basiese en individuele reg op kinders voorrang geniet.

Die konkrete vraag lui watter norme en waardes van die gemeenskap enersyds en watter sosiaal-demografiese probleme andersyds teenoor die wens van die individuele egpaar prioriteit geniet. Uitsprake oor konfrontasies van hierdie aard, naamlik individuele behoeftes teenoor die belange van die gemeenskap, is noodwendig onderhewig aan die sosiologies-sielkundige klimaat van die betrokke gemeenskap asook aan die gegewe geskiedkundige tydperk. Sodanige uitsprake is dus "tydelik" van aard en aan veranderinge onderworpe. Inderdaad is moreel-sedelike waardesisteme en sosiaal-demografiese prioriteite manipuleerbaar en as sodanig dus 'n voedingsbodem vir misbruik en misdaad.

Indien bevind sou word dat sekere egpare nie aan kinders gehelp kan word nie omdat die nodige navorsing en behandeling vir die gemeenskap moreel-sedelik of vanweë ander prioriteite onaanvaarbaar blyk te wees, dan moet ' $n$ verdere belangrike gesigspunt in hierdie verband genoem word. Met huweliksluiting het man en vrou mekaar met alle bekende en onbekende tekortkominge aanvaar. Indien hulle onvrugbaarheid nie deur konvensionele mediese behandeling binne die raamwerk van 'n erkende moreel-sedelike waardesisteem te bowe gekom kan word nie, sal daardie egpaar sy kinderloosheid as "onveranderbaar" moet aanvaar. Die gemeenskap andersyds wat teenoor daardie individuele egpaar hierdie standpunt inneem en daarom aan hulle verdere hulp ontsê, sal dit ten volle moet kan verantwoord.

Samevattend blyk dit dat die verwekking van kinders in toekoms geen private aangeleentheid meer sal bly nie maar moontlik in terme van 'n demografiese en eugenetiese "voortplantingsbeleid" toenemend amptelik gereël sal word. Die vraag na die moreel-etiese 
toelaatbaarheid van sodanige manipulasie loop uit op die bevinding dat die mens nie aanspraak op 'n basiese en prinispiële reg op kinders kan maak nie. Dit blyk verder dat die verwekking van kinders van pragmatiese, sosiaal-demografiese prioriteite asook van moreel-sedelike waardesisteme van elke gemeenskap afhanklik is. Dienooreenkomstig kom die kontinue oorgang van "toelaatbare/aanvaarbare" na "verbode/verwerplike" medies-genetiese navorsing en behandeling ter oorkoming van individuele gevalle van onvrugbaarheid op die voorgrond. 'n Uitspraak oor hierdie aangeleentheid lê enersyds ingebed in die konfrontasie van individuele behoeftes teenoor openbare belange en andersyds in die bepalinge van die moreel-sedelike waardesisteem en die sosiaaldemografiese prioriteite.

(b) DIE REG OP GESONDE KINDERS.

Naas die vermeende prinsipiële reg van egpare op kinders in die algemeen, wat hierbo bespreek is, moet ook die vraag of individuele egpare teenoor die gemeenskap 'n aanspraak op geneties "gesonde/normale" kinders aanhangig kan maak, ondersoek word. Die oorweldigende openbare reaksie hierop is sekerlik dat die voorkoming van erfbare abnormaliteite en genetiese siektes by babas die hoogste prioriteit behoort te geniet. Die navorsing op hierdie gebied word dan ook gewoonlik deur openbare middele en namens die betrokke gemeenskappe ruim ondersteun. Die fenomenale vooruitgang op die terrein van die diagnostiese en terapeutiese metodes kan juis in ' $n$ besondere mate aan hierdie prioriteit, naamlik die voorkoming van geneties abnormale babas, toegeskryf word.

Verdere vooruitgang ten einde nog meer genetiese siektes en abnormaliteite af te wend vereis egter verdere medies-tegniese navorsing en manipulasie. Hier kan vervolgens twee alternatiewe standpunte ingeneem word: Daar kan enersyds aangevoer word dat die verligting en voorkoming van genetiese abnormaliteite sonder die geringste voorbehoude voorrang geniet en dus ten alle koste voortgesit behoort te word. Andersyds, met die oog op die tipe eksperimente wat reeds gedoen word (volgens Deel II) en die probleme wat daaruit voortvloei word daar ook toenemend gewaarsku. Daar word beklemtoon dat die tipe navorsing wat hier ter sake is in terme van 'n sekere moreel-sedelike waardesisteem bedenklik is. Die konkrete vraag lui of verdere vooruitgang, dit wil sê die verdere bekamping van genetiese abnormaliteite, in terme van die prys wat dit kos, dit wil sê die norme en waardes wat daarby in die gedrang kom, nog regverdigbaar is. Weer eens tree die probleem van kontinue oorgange, van "regverdigbare/toelaatbare" na "verbode" medies-genetiese na- 
vorsing en behandeling op die voorgrond. Indien daar gevoel word dat die limiet van "regverdigbare/toelaatbare" navorsing en behandeling bereik is, dan sal verdere individuele aansprake op voorkoming van abnormale babas afgewys moet word. Op hierdie stadium sal dan teenoor die gebrekkige kind en sy ouers erken moet word dat aan hulle aanspraak op voorkoming en genesing bewustelik nie gehoor gegee word nie (hoewel dit teoreties met spesifieke medies-genetiese optrede moontlik sou gewees het), omdat dit in terme van 'n sekere moreel-sedelike waardesisteem as "ontoelaatbaar" beskou word.

Die betrokke egpaar kom hier voor die besef te staan dat hulle abnormale kind sy gebrekkigheid van hulleseif oorgeërf het. Hulle kom dus voor hulle eie genetiese tekortkoming .e staan;'n tekortkoming wat egter in die vorm van 'n verborge "genetiese las" (volgens Deel I) wyd verspreid in die gemeenskap mag voorkom. Die gemeenskap eis egter slegs van die betrokkenes om in hulle tragiese noodlot te berus, terwyl dit eintlik 'n "sosiale las" en noodlot is wat die gemeenskap as geheel behoort te verduur aangesien elke lid van die gemeenskap 'n potensiële draer daarvan mag wees. Die gemeenskap wat 'n sodanige "privatisering" van 'n "sosiale" tragiese noodlot bepleit, sal pertinent op die woorde van Paulus - wat menige genetikus juis in hierdie verband reeds aangehaal het - gewys moet word:

En op die wat sterk is, rus die verpligting om die swakhede te dra van die wat nie sterk is nie ... (Romeine 15:1)

Inderdaad kom hier die noodsaaklikheid om die individuele noodlot van die betrokke egpare en hulle abnormale kinders algemeen te dra dringend na vore.

Juis in aansluiting by die standpunt dat die gemeenskap in die algemeen die gevolge van erfbare abnormaliteite eweneens behoort te $d r a$, moet 'n verdere, sekondêre argument genoem word. Daar word dikwels deur eugenetici beklemtoon dat die pasiënte met ernstige erfbare abnormaliteite meestal in spesiale inrigtings en op koste van die gemeenskap onderhou moet word. In die lig van sodanige verpligting wat op die gemeenskap rus, word daar gemeen dat laasgenoemde ook meer seggenskap by die voorkoming van geneties abnormale babas behoort te hê. Namens die gemeenskap sou cie staat dus mag optree (of selfs daartoe verplig kan word) om die verwekking van verdere abnormale babas te verhoed. Die maatreëls wat hier te ter sprake is, is eugeneties van aard en behoort volgens die voorstaanders daarvan toegepas te word waar en wanneer die vooruitsig op die geboorte van 'n abnormale baba bestaan. Byvoorbeela deur 
eugenetiese aborsie, genetiese raadgewing, sterilisasie ensovoorts behoort die kanse op verwekking van abnormale bałas verminder te word.

\section{NORME, WAARDES EN DEFINISIES.}

Soos in hierdie gedeelte telkemale tot uiting gebring is, is die eugenetiese en medies-genetiese maatreëls onder andere gegrond op moreel-sedelike norme en waardes asook op feitelike definisies en op subjektiewe beredenering en beoordeling. Dit geld in die eerste plek vir die vraag na die prinsipiële toelaatbaarheid van eugenetiese en medies-genetiese optrede in die algemeen asook na die regverdigbaarheid en toelaatbaarheid van spesifieke eugenetiese maatreëls in die besonder. Vervolgens is die ideale en doelstelling van eugenetiese optrede onder die soeklig geplaas en daar is gevind dat veral die einddoel van positiewe eugenetika onoortuigend gedefinieer is. Hier duik die vraag op of enige geslag alle nakomende geslagte by wyse van 'n onveranderbare "eugenetiese testament" so onverbiddelik durf bind. Die eugenetiese doelstellings en die definisies is met verloop van millennia sekerlik aan veranderinge onderworpe en dus noodwendig relatiewe begrippe. Streng toegepaste positiewe eugenetika loop dus gevaar om ooreenkomstig die toenemende "effektiwiteit" daarvan al hoe meer tot 'n absurditeit te ontaard.

Hoewel ten opsigte van negatiewe eugenetika die probleme nie so swaarwegend is nie, is dit hier die kontinue oorgange en definisies wat hoofbrekens besorg. Vergelyk byvoorbeeld, "nog nie" en "reeds" individuele lewe, "siek/abnormale" en "gesonaie/normale" babas, "toelaatbare" en "ontoelaatbare/verbode" aborsies of medies-genetiese navorsing, die "reg" op kinders, ensovoorts. Hier kom inderdaad 'n veeldimensionele kompleksiteit na vore wat filosofies-teologiese, sielkundige en juridiese beginsels - naas die voor-die-hand-liggende feitelike medies-genetiese situasie - omvat, elk waarvan grondige oorweging vereis.

\section{TEENSTR YDIGE BELANGE}

In die voorafgaande gedeeltes is telkemale aangetoon hoedat die gevolgtrekkings by die bespreking van die afsonderlike fasette van eugenetika dikwels op 'n teenstrydigheid van belange uitloop. Daar is in die eerste plek die verwyt wat somtyds benadruk word (volgens Wagner (1969) en sommige van sy medeskrywers), dat die natuurwetenskaplikes in die algemeen en spesifiek sommige bioloë (genetici en medici) in hulle navorsing dikwels, met die behoeftes en sienswyses van die gemeenskap uit voeling sou wees, en selfs dikwels ook met die belange en die moreel-sedelike waardesisteem daarvan in 
botsing sou kom. Hierdie aspek word hieronder verder bespreek. Hierbenewens is dit telkemale die verwagtinge en behoeftes van enkelinge, egpare of sekere groepe binne die afsonderlike gemeenskappe wat aanspraak op sekere medies-genetiese of eugenetiese dienste maak, wat moontlik teen die belange en moreel-sedelike waardesisteem van hulle onderskeie gemeenskap mag indruis. Vergelyk byvoorbeeld Watson: ". . . . (the) potentially militant lobby of infertile couples", wat op kunsmatige homoloë of heteroloë inseminasie of op fetusoorplantings sou aandring. Soortgelyke teenstelling tussen individuele belange en dié van die gemeenskap tree ook by die ander eugenetiese of mediesgeneties maatreëls, byvoorbeeld by verpligte sterilisasie en eugenetiese aborsie'; na vore.

Natuurlik sal enige gemeenskap, via sy openbare inrigtings en dienste en binne die raamwerk van sy aanvaarde moreel-sedelike waardesisteem aan sodanige individuele of groepsversoeke gehoor gee. Elke gemeenskap sal egter duidelikheid oor die grense van sy moreelsedelike waardesisteem moet kry en sal alle dienooreenkomstige besluite in die openbaar moet kan verantwoord. Die probleem om in die lig van sulke netelige, vaag-omlynde en terselfdertyd ook swaarwegende alternatiewes aan alle belanghebbende partye reg te laat geskied, word aansienlik bemoeilik deur die plek- en tydsgebondenheid van elke moreel-sedelike waardesisteem. Met die heersende intensiteit van kommunikasie is die sosio-sielkundige klimaat van elke gemeenskap 'n wispelturige veranderlike waaruit van tyd tot tyd "aangepaste" moreel-sedelike waardesisteme gebore mag word. Met die oog op eugenetiese en medies-genetiese maatreëls vereis sodanige toedrag van sake deeglike oorweging en besonne optrede.

\section{JURIDIESE IMPLIKASIES}

Die veelvuldige moontlikhede en kombinasies van medies-genetiese manipulasie van die mens en sy voortplanting vereis nuwe juridiese beginsels en benaderings. Die mees triviale probleme sal wees om oor die wettige status van kinders wat op een van die veelvuldige onkonvensionele metodes verwek en/of gebore word, om oor die kwessie van owerspel asook oor die identiteit van kinders wat 'n voorgeboortelike weefseloorplanting (chimeravorming) ondergaan, of deur klonering ontstaan het, nuwe duidelikheid te verky. 'n Meer subtiele probleem is die vraag of van die embriologiese en medies-genetiese navorsing en manipulasies (volgens Deel II) nie teen die "waardigheid" en basiese "regte" waarop elke mens kragtens sy menswees aanspraak kan maak, indruis nie. Indien hierdie gesigspunt, juridies gesproke, van toepassing sou wees, dan sal bepaal moet word vanaf 
watter voorgeboortelike ouderdom en vanaf watter graad van "normaliteit" op sodanige "menswaardigheid" en "mensereg" aanspraak gemaak kan word. Vraag is of wesens wat hulleself by sodanige indeling buite die arbitrêre grense daarvan sou bevind, dan - ooreenkomstig die strekking van die argument - sodanige aansprake verbeur? Die ergste gevalle van abnormaliteit, waar die "menslike" wesens bloot vegeterende liggame is, mag moontlik hier'n tersaaklike voorbeeld wees.

Die wettiging van gewone of eugenetiese aborsies, heteroloë en homoloë inseminasies en ander tegnieke hoort vandag reeds tot die mees aktuele juridiese besprekings. Terwyl die vernietiging van in vitro fetusse, chimeravormings, klonerings, fetusoorplantings en verpligte sterilisasies, oorweginge is wat reeds langs die gesigseinder van juridiese denke begin opduik. Alvorens laasgenoemde praktyke on wettig verklaar kan word, moet onder andere oor aspekte soos die "wese", "uniekheid" en die "eenheid" asook oor baie ander hoedanighede van die mens besin word. Die feit dat natuurlike klone (twee van een persoon, naamlik identiese tweelinge, ten koste van die "uniekheid" van enkele mense) en natuurlike chimeras (twee persone in een, ten koste van die "eenheid" van daardie mense) voorkom, sal hierdie probleem nog verder bemoeilik. Die juridiese implikasies van eugenetiese en medies-genetiese optrede kan hier slegs gedeeltelik genoem word. Dié onderwerp vereis 'n deeglike en afsonderlike studie van sy eie!

\section{POLITIEKE IMPLIKASIES.}

Eugenetiese en medies-genetiese optrede word baie dikwels in 'n politieke perspektief geplaas. Meestal is die gevolgtrekking van so 'n benadering dat regerings op min of meer subtiele of outoritêre wyse alle moontlikhede van manipulasie benut ten einde sekere politieke ideologiese ambisies te kan verwesenlik. Hierdie gedagtegang word dan dikwels in verband gebring met ' $n$ diktatoriale regerende klas wat die mees verreikende manipulasies toepas om hulle magsposisie te verstewig asook om, eweneens deur misbruik van hulle moontlikhede van manipulasie, ander bevolkingsklasse tot biologiessielkundige wesens van ondergeskikte en minderwaardige formaat te verdoem. Hoewel daar 'n greintjie van egte gevaar in hierdie moontlikheid mag steek, kring die tema in so 'n mate uit dat geen einde aan dié perkelose spekulasie gemałk kan word nie.

In hierdie artikelreeks is slegs rekening gehou met 'n demokratiese regeringstelsel waar die gemeenskap op effektiewe wyse uiting aan hulle wil en wense kan gee, waar die bewindhebbende regerings die 
gemeenskap verteenwoordig en laasgenoemde dus vir alle wetgewing medeverantwoordelikheid moet aanvaar. In sodanige state is alle eugenetiese en medies-genetiese optrede - of gebrek aan optrede 'n aangeleentheid waarvoor die gemeenskap naas die bewindhebbers eweneens verantwoordelik is.

\section{MISVERSTANDE EN NOODWENDIGHEID VAN KOMMUNI-} KASIE.

Eugenetika in al sy fasette en implikasies is tot dusver hoofsaaklik deur natuurwetenskaplikes van die betrokke vakrigtings by baie geleenthede en in tallose artikels bespreek. Een gedagte wat soos 'n goue draad deur al hierdie vakwetenskaplike publikasies loop, is die algemene wens om met die sosiale wetenskappe en met die gemeenskap in die algemeen (naamlik met organisasies en instellings) intensiewer te kommunikeer. Daar blyk inderdaad 'n dringende behoefte aan 'n raamwerk van aanvaarbare konvensies, aan 'n duidelike moreelsedelike waardesisteem waarbinne die navorsing kan plaasvind asook aan 'n forum waar die navorsing en die implikasies daarvan vrymoediglik bespreek kan word te wees. Verglyk in hierdie verband die volgende aanhalings:

The trailing social sciences need to stride out to catch up with the rapid advance of the physico-biological sciences.

(Sinclair en Anderson, 1964).

Certainly, the challenges of these new responsibilities should not be the sole province of physicians, but one that must be shared with society.

(Milunsky et al, 1970)

... more than a few biologists share (the) concern that science 'will give us gene therapy before society is prepared for it'. (Rabovsky, 1971)

Rational discussion is needed about the emerging social issues involved in these studies. (Edwards, 1971)

The increasing tempo of scientific achievement now seems to demand that social attitudes are helped to keep pace with or even direct new issues as they arise.

We believe that it is important at this stage to elaborate the emerging issues in order to give time for defining and evolving social attitudes on which to base rules of conduct for scientists and society.

... the achievements of science catch unprepared a society that lacks either ready made attitudes or the institutional means of forming new ones. 
When scientists clearly foresee potential conflicts with existing rules of society arising from their work, paradoxically both human progress and scientific freedom may hang on their activism in arenas generally regarded as social or political. Scientists may have to make disclosures of their work and its consequences that run against their immediate interests; they may have to stir up public opinion, even lobby for laws before legislatures, in the hope that the attitudes of society as evidenced in its laws will mature at a rate not too far behind the transition of scientific discovery into technological achievement. (Edwards and Sharpe, 1971).

Hierdie aanhalings beklemtoon hoedat natuurwetenskaplikes op ooreenkomstige ontwikkeling en vooruitgang op geesteswetenskaplike terrein en by die gemeenskap aandring. 'n Mens moet ook kennis daarvan neem dat eugenetici en die betrokke medies-genetiese navorsers hulleself beywer om die gemeenskap by hierdie ontwikkeling te betrek. Hulle beroep op die geesteswetenskappe en die gemeenskap om medeverantwoordelikheid te aanvaar dui op ' $n$ geordende manier van hantering. Hiermee is inderdaad 'n basis vir vrugbare kommunikasie geskep; wat nie die tradisionele verdeling van gesag en verantwoordelikheid verontagsaam nie. Sodanige kommunikasie word egter deur probleme wat nie alleen deur bereidwilligheid en tegemoetkomendheid oorkom kan word nie, belemmer: daar heers naamlik 'n taalverwarring van Babiloniese formaat! Hierdie misverstande en verwarringe is juis in verband met eugenetika en die medies-genetiese behandeling van die mens besonder akuut. Sonder om hierdie probleem tot in al sy polemiese uithoeke na te gaan (volgens die boek van Wagner, 1969) sal enkele gedagtes daaromtrent tog van pas wees.

Die idealisme en naasteliefde van die mens naas die humanisme vorm deel van die voedingsbodem waaruit eugenetika ontstaan het, terwyl die rasionale natuurwetenskaplike intellek en die eksperimentele navorsing die praktiese benadering en implementering van eugenetika bepaal. Eugenetika is dus gegrond op die volheid van die aspirasies, ambisies en vermoëns van die mens en dit maak aanspraak daarop om vir sy toekomstige voortbestaan en vir sy volwaardige mens-wees noodsaaklik te wees. Indien hier ligtelik tot ' $n$ polemiek oorgegaan word, dan getuig dit van 'n onvolledige begrip van sowel die kompleksitiet van die onderhawige probleem, asook van die inherente drang van die mens om die natuur, insluitende sy eie natuur, te ken en te beheer. Dit is geen toevalligheid nie dat die mens homself na Adam en Eva herlei; hy sal met daardie deugde en tekortkominge 
verlief moet neem. Mag iemand dus 'n ligtelike verwyt uitspreek omdat die mens voortdurend daarna streef om verdere kennis en mag van die boom te pluk? Oor millennia heen deel die mensdom sonder vingerwysing in die "goeie" - in die vorm van kulturele en tegnologeise vooruitgang - van daardie einste sondeval. As dit nou by die vermeende "euwels" daarvan, dit wil sê van ons mens-wees kom, durf daar ook geen ruimte vir engele en duiwels wees nie!

Terwyl daar op aarde geen terugkeer na die onkunde en onskuld yan weleer kan wees nie, net so min kan ons van die huidige stand van wetenskap, kennis en tegnologie met alle probleme wat daaruit mag voortvloei, wegskram. Deur die aktiewe optrede van die mens het die "gees" - soos die Oosterse sprokie dit aan ons nalaat - reeds uit die bottel ontsnap. Dit sou 'n dwase, onbegonne taak wees om hom weer te probeer inperk, en om die ontwikkeling van millennia ongedaan te probeer maak. Inteendeel, daar sal uitgegaan moet word van die heersende en die afsienbare werklikheid. Hierdie saaklike nugtere uitgangsituasie behoort sonder emosies of polemiek as sodanig - maar nie noodwendig as finaal en onafwendbaar nie aanvaar te word. Die volgende stap behoort te wees om die toekomstige ontwikkeling in 'n geordende en verantwoordbare baan te laat probeer plaasvind, dit wil sê sonder die (in elk geval) nuttelose poging van 'n totale onderdrukking en gevolglike stilstand, sonder polemiek asook sonder alle utopiese en verregaande absurditeite. Hiervoor staan die tekens inderdaad gunstig solank die gemeenskap verantwoordend en regulerend die hef in die hand behou - soos wat dit tradisionelerwyse die geval is. Die vermeende vloek of vermeende seën van eugenetika en medies-genetiese behandeling lê dus opgesluit in die mate waarin die gemeenskap oordeelkundig en regulerend optree. Hierdie is 'n grootse en noodsaaklike taak, die vervulling waarvan enige gemeenskap tot eer sal strek. Miskien is bogenoemde egter 'n te optimistiese siening van die rol en funksie wat die gemeenskap daadwerklik kan vervul. Terwyl daardie bedeling dus 'n ideaal voorstel wat nagestreef behoort te word, is die praktiese verloop van sake tog anders.

In hierdie gedeelte is probeer om by wyse van 'n prinsipiële bespreking alle relevante vraagstukke aangaande eugenetiese en mediesgenetiese optrede krities te ontleed. Op grond van 'n sodanige $a$ priori ontleding skyn dit feitlik onmoontlik te wees om tussen die Scylla en Charybdis van wetenskaplike probleme en moreel-sedelike bedenkinge ' $n$ enigsins regverdigbare en aanvaarbare weg vir optrede te vind. In die praktyk van ons tyd wil dit egter voorkom asof die 
natuurwetenskappe 'n ongeëwenaarde vooruitgang ondervind waarop die gemeenskap nie altyd voorberei is nie en wat ook nie altyd as wenslik aanvaar word nie. In verband met die eugenetiese en mediesgenetiese vooruitgang in die besonder, beteken dit dat die gemeenskap gewoonlik a posteriori tot gegewe ontwikkelinge stelling moet neem. Met die implementering van sekere eugenetiese en mediesgenetiese maatreëls dus skynbaar onafwendbaar en die moreel-sedelike, teologies-filosofiese en juridiese basis van optrede egter onvolledig uitgestippel kom die sentrale dilemma van hierdie onderwerp na vore. Hierdie dilemma sal deur sowel die natuurwetenskaplikes en die gemeenskap as geheel tegemoet gegaan moet word.

\section{SLOTOPMERKING}

Toe die gevierde Atheense kunstenaar, bou- en ambagsmeester, Daedalos, sy bannelingsoord op Kreta wou verlaat, het hy vir hom en sy seun Ikaros, uit was en vere vlerke gemaak en daarmee sy legendariese ontvlugting onderneem. Die wyse vader het die gevare van so 'n vlug voorsien en vir Ikaros gewaarsku om nie te laag na die see af te sak en ook nie te hoog na die son op te styg nie. Na 'n ver ent van vlieg, is die ootmoedige jongeling deur sy wonderbaarlike prestasie verblind en hy besluit om tog die son tegemoet te vlieg. Voordat hy die gevaar waarin hy hom deur sy uitdagende optrede begeef het, kon besef, het die was begin smelt en hy het in die see neergestort. Alleen die ronddrywende vere het vir die eensaam soekende vader die tragiese einde van sy seun verklaar. Die eiland Ikaria waar die lyk van die seun, volgens die legende, uitgespoel en deur sy vader begrawe is, getuig van die onverbiddelik rampspoedige gevolg van daardie daad van onbeskeie voorbarigheid.

Hierdie en baie ander kleurryke legendes van ouds beklemtoon dat die hibris van die mens nie ongestraf oorgesien sal word nie, maar 'n tragiese einde sal vind. Hierdie les, in baie vorme ingeweef in die godsdienste en geestesgeskiedenis van die mens, het tot vandag toe nie sy aktualiteit verloor nie. Wie die eiedunk sou hê dat die mens gloriery ke middelpunt en almagtige eindbestemming van alle skepping sou voorstel, dat die selfverhewe mens dus ook by magte sou wees om verwaand op te tree, vir hom wag daar 'n ontnugtering. Sonder twy fel bevat eugenetiese en medies-genetiese denke ' $n$ komponent van daardie verwaande en rampspoedige menslike hibris wat heeltemal on betaamlik is.

Hierteenoor is dit van pas dat almal wat in hierdie arena beweeg die woorde van Lejeune ter harte neem. 
I believe our response must be guided by two sentiments only humility and compassion. Humility because we must recognize we have no ready-made answers, because geneticists have not broken the secret of the human conditions, and because scientific arguments are of little help in ethical issues; compassion because even the most disinherited belongs to our kin, because these victims are poorer than the poorest, and because the sorrow of the parents cannot be consoled by science.

Ten opsigte van eugenetiese en medies-genetiese optrede sal daar met alle versigtigheid tussen die nougesette grense, soos enersyds neergelê deur ' $n$ roeping en die vanselfsprekenheid om in die lig van menslike nood en behoeftigheid op te tree net waar dit noodsaaklik en wenslik mag wees en andersyds, neergelê deur die afsiening van enige ambisie tot verwaande selfverheffing, deurgestuur moet word. Indien hierdie koers gehandhaaf kan word, bestaan minstens die vooruitsig dat ons, soos Daedalos van ouds, ons noodlot in 'n mate kan verlig, sonder om die son of see te na te kom.

\section{NASKRIF}

In die voorafgaande algemene bespreking is gepoog om van die moreel-sedelike probleme wat verband hou met eugenetiese en medies-genetiese optrede duideliker te omlyn en om die daaruit voortspruitende implikasies uit te stippel. Hierteenoor is daar nie onderneem om afgeronde "antwoorde" en gebruiksklaar "oplossings" aan te bied nie. Die rede wat hoofsaaklik tot hierdie benadering aanleiding gegee het, is om elke leser persoonlik met die onderhawige problematiek te konfronteer. Trouens, die persoonlike verantwoordelikhied wat op elke gemeenskapslid in hierdie verband rus word nie deur die beklemtoning van die rol wat aan die gemeenskap as geheel toe vertrou is, negeer nie. Inteendeel, die optrede van 'n gemeenskap word natuurlikerwyse bepaal deur dié van die individuele gemeenskapslede. In hierdie sin moet elke belanghebbende persoon onder die besef van sy verantwoordelikheid en betrokkenheid gebring word. Hierdie geld in die besonder ook vir die natuurwetenskaplikes wat eugenetika en die medies-genetiese behandeling van die mens as hulle roeping aanvaar het. Dit is duidelik dat hulle 'n grootse taak en verpligting op hulle neem waarvoor hulle vanselfsprekend ook persoonlik verantwoordelikheid moet aanvaar.

\section{H W HITZEROTH}

Afrika-Instituut 